\title{
High Maternal and Low Cord Blood Leptin Are Associated with BMI-SDS Gain in the First Year of Life
}

\author{
Anna Telschow ${ }^{a} \quad$ Nina Ferrarib, c Clara Deibert $^{a} \quad$ Anne Flöck $^{d}$ \\ Waltraut M. Merz ${ }^{d} \quad$ Ulrich Gembruch ${ }^{d}$ Christina Ehrhardt ${ }^{c}$ Jörg Dötsch ${ }^{e}$ \\ Christine Grafc \\ a University Hospital of Cologne, Cologne, Germany; ${ }^{b}$ Cologne Center for Prevention in \\ Childhood and Youth/Heart Center Cologne, University Hospital of Cologne, Cologne, \\ Germany; ${ }^{\circ}$ Department for Physical Activity in Public Health, Institute of Movement and \\ Neurosciences, German Sport University Cologne, Cologne, Germany; d Department of \\ Obstetrics and Prenatal Medicine, University of Bonn Medical School, Bonn, Germany; \\ e Department of Pediatrics and Adolescent Medicine, University Hospital of Cologne, \\ Cologne, Germany
}

\section{Keywords}

Maternal leptin levels · Cord blood leptin · Obesity · Physical activity · Exercise · Offspring · Body mass index $\cdot$ Standard deviation scores

\begin{abstract}
Background: Early infant weight development influences metabolic regulation later in life. For the prevention of obesity and metabolic diseases, it is important to understand the underlying mechanisms in detail. Objectives: This study aims to examine the effects of maternal anthropometric, sociodemographic, and lifestyle factors on maternal and cord blood leptin levels at birth and on the development of body mass index (BMI) standard deviation scores (SDS) in offspring up to 1 year of age. Methods: Seventy-six mother-child pairs were enrolled in this follow-up analysis in a cross-sectional design. Standardized questionnaires were used to collect information regarding maternal anthropometrics, lifestyle habits, and sociodemographic conditions, and newborn weight, or, rather, BMI-SDS, development during the first year of life. Results: Cord blood leptin $(\beta=-0.222, p=0.074)$, maternal leptin $(\beta=0.414, p=0.001)$, and female sex of the offspring ( $\beta=0.385, p=0.003$ ) explained $29.0 \%$ of the variance in BMI-SDS changes in the first year of life. Cord blood leptin was influenced by newborn sex (male; $\beta=$
\end{abstract}

Anna Telschow and Nina Ferrari contributed equally to this work. 
$-0.220, p=0.025)$ and maternal moderate-intensity physical activity in the third trimester ( $\beta=0.265, p=0.007$, corr. $R^{2}=9.2 \%$ ); maternal leptin was influenced by maternal prepregnancy BMI $(\beta=0.602, p<0.001)$ and weight gain during pregnancy $(\beta=0.247, p=0.004$, corr. $\left.R^{2}=35.5 \%\right)$. Conclusions: Higher maternal and lower cord blood leptin levels are associated with a higher BMI-SDS increase during the first year of life. Maternal leptin is influenced by maternal BMI and weight gain during pregnancy, and cord blood leptin is influenced by maternal physical activity; therefore, it can be suggested that an active and healthy maternal lifestyle may play a pivotal and beneficial role in the offspring's weight development.

(C) 2019 The Author(s)

Published by S. Karger AG, Basel

\section{Introduction}

Juvenile overweight and obesity are increasing health issues due to their association with cardiovascular risk factors, metabolic diseases, and orthopedic and psychosocial disorders, for example [1]. In Germany, $16.2 \%$ of girls and $18.5 \%$ of boys aged $14-17$ years are overweight or obese [2]. Childhood obesity is associated with family lifestyle, sociodemographic status, and maternal overweight [2,3].

According to the "German Health Interview and Examination Survey for Adults" (DEGS1), $53.0 \%$ of German women and $67.1 \%$ of German men are overweight or obese [4]. Women of childbearing age are especially affected. Overweight and obese women have a higher risk of excessive weight gain during pregnancy than normal-weight women [5]. Furthermore, obesity is associated with multiple maternal and neonatal complications, such as gestational diabetes mellitus or macrosomia [6]. Correspondingly, macrosomic newborns have an increased risk to remain overweight and to develop subsequent metabolic dysfunctions [7].

Among other factors, leptin appears to play a key role in the underlying (patho)physiological processes. Leptin is a peptide hormone that is associated with the amount of body fat. Consequently, overweight individuals have high leptin concentrations and may also manifest leptin resistance [8]. Physiologically, leptin increases satiety, particularly by regulating hypothalamic regions [8]. It is mainly produced by adipocytes but also by the human placenta. Linnemann et al. [9] showed that $98.0 \%$ of the total placental leptin is released into the maternal circulation, influencing thermogenesis and energy balance.

In terms of offspring weight development, Boeke et al. [10] analyzed the influence of maternal and infant leptin concentrations on the body mass index (BMI) $z$-score after 3 and 7 years of life, and they found an inverse correlation between cord blood leptin concentrations and weight gain in the first 3 years. In contrast, leptin concentrations at the age of 3 years and weight gain up to the age of 7 years were positively correlated.

Weight gain during the first months of life seem to have a pronounced effect on metabolic regulation [11-13]. According to Ekelund et al. [13], weight gain during this early period was associated with metabolic risk factors at 17 years of age. In addition, Kwon et al. [11] showed that the body fat percentage in 19-year-old women was significantly higher in those who experienced a steep increase in BMI during the first year of life than in those who experienced this increase during their second year.

It has been shown that leptin levels can be influenced by physical activity in both pregnant and nonpregnant women [14,15]. Clapp and Kiess [14] demonstrated that women who exercised throughout pregnancy had significantly lower leptin levels at 11, 24, and 36 weeks of gestation than controls.

Existing studies regarding weight gain during the first months of life did not take maternal leptin levels $[16,17]$ or lifestyle factors $[16,18]$ into consideration; therefore, to develop 
Telschow et al.: Association between Leptin and BMI-SDS in Early Life

tailored preventive measures as early and sustainably as possible, it seems to be important to detect underlying mechanisms and potential influencing factors, e.g., lifestyle. Hence, we examined the association of maternal anthropometric, lifestyle, and sociodemographic factors between both maternal and cord blood leptin concentrations at birth and the postnatal weight development measured as the change in BMI standard deviation score (SDS) during the first year of life.

\section{Materials and Methods}

\section{Recruitment and Sample Size}

This is a follow-up study of a cross-sectional study that was performed between December 2013 and April 2014 in the obstetric unit of a tertiary referral center. Exclusion criteria were preterm delivery, multiple pregnancy, or known fetal malformations. Of the original 123 mother-child pairs included in the baseline study (T0), 6 were excluded due to postnatal complications, and 4 women could not be contacted because they changed their address. The remaining 113 women received a questionnaire to which 78 responded (T1). Ultimately, complete data sets were available for 76 mother-child pairs (response rate 67.3\%).

\section{Anthropometric and Demographic Data}

Baseline demographic and prepregnancy anthropometric data, as well as newborn data (birth weight and sex), were obtained from the patient files and the perinatal database, as described by Flöck et al. [19] and Deibert et al. [20]. Sociodemographic data included the level of education, and a review by Shrewsbury and Wardle [3] revealed that parental education is more consistently associated with adiposity than other indicators of the sociodemographic status.

Maternal prepregnancy BMI was categorized into the following groups: underweight $\left(<18.5 \mathrm{~kg} / \mathrm{m}^{2}\right)$, normal weight $\left(18.5-24.9 \mathrm{~kg} / \mathrm{m}^{2}\right)$, overweight $\left(25.0-29.9 \mathrm{~kg} / \mathrm{m}^{2}\right)$, or obese $\left(\geq 30.0 \mathrm{~kg} / \mathrm{m}^{2}\right)[21]$.

Furthermore, maternal mid-arm and mid-leg circumferences were measured on the right side to the nearest $0.1 \mathrm{~cm}$ with a nonextensible, flexible tape. Maternal skinfold thickness of the triceps was measured by a single observer using a Harpenden skinfold caliper (John Bull British Indicators Ltd., Harpenden, UK) with a constant pressure of $10 \mathrm{~g} / \mathrm{mm}^{2}$. The procedure was carefully standardized, and the measurements were made in triplicate on the right side of the body, after which the results were averaged [22]. The total upper arm area, upper arm fat estimate, and upper arm fat-free mass estimate were calculated according to RollandCachera et al. [23]. Data about maternal anthropometrics at T1 were collected in modified standardized questionnaires [24].

\section{Lifestyle Characteristics}

The Pregnancy Physical Activity Questionnaire described by Chasan-Taber et al. [25] was used to evaluate maternal physical activity, which was measured in metabolic equivalents (METs) [26] by multiplying the time spent on each activity by its intensity and classified into 4 different intensity groups according to MET levels: sedentary ( $<1.5$ METs), and light (1.5-3.0 METs), moderate (>3.0-6.0 METs), or vigorous intensity ( $>6$ METs).

A semiquantitative food frequency questionnaire (FFQ) adapted from the FFQ described by Meltzer et al. [27] was used to evaluate dietary habits. To assess the quality of diet during pregnancy, the healthy eating index (HEI) was calculated as described elsewhere [28]. At T1, modified standardized questionnaires [24] were used to collect data regarding maternal smoking status and breastfeeding conditions. 
Telschow et al.: Association between Leptin and BMI-SDS in Early Life

\section{Analytical Procedures and Leptin Analyses}

Laboratory values were generated from maternal venous blood taken on admission to the labor ward and from umbilical cord blood taken from the placental part of the umbilical cord directly after clamping. As described by Flöck et al. [19], the samples were stored at $4{ }^{\circ} \mathrm{C}$ until centrifugation (4,000 rpm for $10 \mathrm{~min})$. Afterwards, serum was separated and stored at $-70^{\circ} \mathrm{C}$. All samples were thawed only once, and the measurements were made in duplicate. A Tecan reader (Nano Quant Infinite M200 Pro, Switzerland) was used to measure total leptin concentrations by a direct sandwich ELISA kit from Merck/Millipore, Germany, as described by Deibert et al. [20].

\section{Physical Development}

The participants were asked to report the somatic development of their newborns as measured in the well-child visits over the past 12 months (U1-U6). These examinations are 6 routine checkups performed by a pediatrician, in which information regarding height, body weight, and head circumference are collected [29]. They take place at the following time points: U1: immediately after birth; U2: 3rd-10th day; U3: 4th-5th week; U4: 3rd-4th month; U5: 6th-7th month; U6: 10th-12th month of life. BMI was calculated and classified into the following categories: a BMI < 10th percentile for age and sex was classified as underweight; a BMI >90th percentile for age and sex was classified as overweight; and a BMI >97th percentile for age and sex was classified as obese [30]. For further analysis, we calculated the age- and sex-dependent BMI-SDS [31].

\section{Statistical Analysis}

Data analysis was performed using the IBM SPSS Statistics 23.0 software (IBM Corp., Armonk, NY, USA), and mean values and standard deviations (SD) were calculated using descriptive statistics to present anthropometric data. The $t$ test was used to compare 2 groups; for various groups, one-way analysis of variance was used. The $\chi^{2}$ test was used to analyze correlations between 2 nominal variables. Linear regression analyses were performed to analyze individual factors that had an impact on the development of BMI-SDS from U1 to U6 (dependent variable). A multiple linear regression model with change in BMI-SDS from U1 to U6 as the outcome variable was adjusted for total physical activity in the third trimester, weight gain during pregnancy, maternal prepregnancy BMI, maternal and cord blood leptin levels, birth weight percentile, and offspring sex. In preliminary modeling, additional potential confounding variables were included, but they did not significantly change exposure-outcome associations (change in BMI-SDS as the outcome variable): total area, fat area, and muscle area of the upper arm, maternal total activity before pregnancy and in the first and second trimesters, sedentary and moderate-intensity activity in the third trimester, HEI, breastfeeding, maternal level of education, and maternal smoking behavior (T0). A second linear regression analysis was performed to analyze significant determinants of maternal leptin (outcome variable). We adjusted this model for the total area and fat area of the upper arm, total physical activity in the third trimester, HEI, maternal prepregnancy BMI, and weight gain during pregnancy. In preliminary modeling, upper arm circumference, upper leg circumference, skinfold thickness, triceps thickness, and sedentary/light and moderate physical activity in the third trimester were also included; however, they did not significantly change exposure-outcome associations (maternal leptin as the outcome variable). To explore significant determinants of cord blood leptin (outcome variable), a third linear regression analysis was performed. We adjusted the model for the total area and fat area of the upper arm, total and moderate physical activity in the third trimester, maternal prepregnancy BMI, weight gain during pregnancy, and offspring sex. In preliminary modeling, sedentary and lightintensity physical activity in the third trimester, maternal leptin, HEI, skinfold thickness, 
Table 1. Maternal anthropometry, lifestyle, and sociodemographic factors (T0, T1) and offspring data

\begin{tabular}{|c|c|c|c|c|}
\hline & $n$ & Mean \pm SD or $n(\%)$ & Min & Max \\
\hline Weight before pregnancy, kg & 76 & $70.3 \pm 14.9$ & 47.0 & 133.0 \\
\hline Height $\mathrm{T} 0, \mathrm{~cm}$ & 76 & $168.7 \pm 7.3$ & 149.0 & 186.0 \\
\hline BMI before pregnancy, $\mathrm{kg} / \mathrm{m}^{2}$ & 76 & $24.7 \pm 4.8$ & 17.2 & 42.0 \\
\hline \multicolumn{5}{|l|}{ Maternal BMI classes } \\
\hline Underweight & 76 & $2(2.6)$ & & \\
\hline Normal weight & 76 & $49(64.5)$ & & \\
\hline Overweight & 76 & $15(19.7)$ & & \\
\hline Obese & 76 & $10(13.2)$ & & \\
\hline Weight gain during pregnancy, $\mathrm{kg}$ & 76 & $15.4 \pm 6.0$ & 1.6 & 30.3 \\
\hline Gestational age at delivery, days & 76 & $275.4 \pm 8.7$ & 258.0 & 290.0 \\
\hline Mid-arm circumference, cm & 73 & $27.3 \pm 3.4$ & 18.0 & 41.0 \\
\hline Leg circumference, $\mathrm{cm}$ & 70 & $50.5 \pm 6.7$ & 39.0 & 68.6 \\
\hline Skinfold thickness of the triceps, $\mathrm{cm}$ & 73 & $21.7 \pm 6.5$ & 11.8 & 51.7 \\
\hline \multicolumn{5}{|l|}{ Upper arm } \\
\hline Total area, $\mathrm{cm}^{2}$ & 72 & $60.1 \pm 15.6$ & 25.8 & 133.8 \\
\hline Fat area, $\mathrm{cm}^{2}$ & 72 & $30.3 \pm 13.3$ & 15.2 & 106.1 \\
\hline Muscle area, $\mathrm{cm}^{2}$ & 72 & $29.8 \pm 8.5$ & 10.6 & 62.7 \\
\hline \multicolumn{5}{|l|}{ Total activity, METs } \\
\hline 1st trimester & 69 & $316.8 \pm 140.5$ & 44.1 & 738.3 \\
\hline 2nd trimester & 69 & $310.8 \pm 135.0$ & 132.2 & 781.7 \\
\hline 3rd trimester & 69 & $268.2 \pm 122.4$ & 97.2 & 869.7 \\
\hline \multicolumn{5}{|l|}{ Sedentary activity, METs } \\
\hline 1st trimester & 69 & $92.0 \pm 44.8$ & 5.5 & 194.1 \\
\hline 2nd trimester & 69 & $93.5 \pm 44.6$ & 5.5 & 194.1 \\
\hline 3rd trimester & 69 & $93.1 \pm 44.2$ & 5.5 & 194.1 \\
\hline \multicolumn{5}{|l|}{ Light-intensity activity, METs } \\
\hline 1st trimester & 69 & $108.1 \pm 58.2$ & 0.0 & 259.9 \\
\hline 2nd trimester & 69 & $110.3 \pm 54.4$ & 14.2 & 260.9 \\
\hline 3rd trimester & 69 & $101.2 \pm 55.2$ & 8.2 & 259.9 \\
\hline \multicolumn{5}{|l|}{ Moderate-intensity activity, METs } \\
\hline 1st trimester & 69 & $114.1 \pm 116.1$ & 0.0 & 516.4 \\
\hline 2nd trimester & 69 & $105.1 \pm 113.2$ & 0.0 & 545.0 \\
\hline 3rd trimester & 69 & $73.4 \pm 88.4$ & 0.0 & 476.7 \\
\hline \multicolumn{5}{|l|}{ Vigorous-intensity activity, METs } \\
\hline 1st trimester & 69 & $2.5 \pm 5.7$ & 0.0 & 33.1 \\
\hline 2nd trimester & 69 & $0.8 \pm 1.9$ & 0.0 & 10.6 \\
\hline 3rd trimester & 69 & $0.3 \pm 0.9$ & 0.0 & 4.9 \\
\hline Healthy nutrition & 70 & $23(30.3)$ & & \\
\hline Breastfeeding (yes) & 76 & $67(88.2)$ & & \\
\hline Smoking in pregnancy (yes) & 76 & $3(3.9)$ & & \\
\hline \multicolumn{5}{|l|}{ Education } \\
\hline Secondary general school & 70 & $2(2.6)$ & & \\
\hline Intermediate school & 70 & $8(10.5)$ & & \\
\hline Grammar school & 70 & $60(78.9)$ & & \\
\hline Birth weight, g & 76 & $3,416.0 \pm 0.477 .4$ & $2,200.0$ & $4,970.0$ \\
\hline \multicolumn{5}{|l|}{ Body mass index, $\mathrm{kg} / \mathrm{m}^{2}$} \\
\hline U1 & 76 & $13.0 \pm 1.3$ & 9.6 & 15.6 \\
\hline U2 & 74 & $12.2 \pm 1.2$ & 8.9 & 15.2 \\
\hline U3 & 76 & $14.5 \pm 1.6$ & 11.1 & 17.9 \\
\hline U4 & 76 & $16.1 \pm 1.6$ & 11.9 & 20.7 \\
\hline U5 & 76 & $16.9 \pm 1.6$ & 13.5 & 21.3 \\
\hline U6 & 76 & $16.6 \pm 1.4$ & 14.0 & 19.9 \\
\hline Gain U1-U6 & 76 & $3.6 \pm 1.6$ & -0.8 & 6.8 \\
\hline
\end{tabular}


Telschow et al.: Association between Leptin and BMI-SDS in Early Life

Table 1 (continued)

\begin{tabular}{lcccc}
\hline & $n$ & Mean \pm SD or $n(\%)$ & Min & Max \\
\hline BMI-SDS & & & & \\
$\quad$ U1 & 76 & $0.3 \pm 1.0$ & -2.4 & 2.4 \\
$\quad$ U6 & 76 & $-0.3 \pm 1.4$ & -4.1 & 5.4 \\
$\quad$ Change U1-U6 & 76 & $-0.3 \pm 1.4$ & -4.1 & 5.4 \\
Male sex & 76 & $34(44.7)$ & & \\
\hline
\end{tabular}

Table 2. Leptin concentrations

\begin{tabular}{lllll}
\hline & $n$ & Mean \pm SD & Min & Max \\
\hline Maternal leptin, ng/mL & 68 & $22.1 \pm 18.1$ & 1.0 & 83.3 \\
Cord blood leptin, ng/mL & 68 & $8.8 \pm 7.3$ & 1.2 & 41.1 \\
\hline
\end{tabular}

triceps thickness, and maternal smoking behavior (T0) were also included, but they did not change exposure-outcome associations (cord blood leptin as the outcome variable). A value of $p \leq 0.05$ was defined as significant.

\section{Results}

Maternal anthropometrics, lifestyle and sociodemographic data, as well as offspring data are displayed in Table 1 . Of the total offspring, 55.3\% were female.

The mean maternal total leptin level at delivery was $22.1 \mathrm{ng} / \mathrm{mL}( \pm 18.1 \mathrm{ng} / \mathrm{mL})$, and the mean cord blood leptin level was $8.8 \mathrm{ng} / \mathrm{mL}( \pm 7.3 \mathrm{ng} / \mathrm{mL}$ ) (Table 2). The results of multiple linear regression analyses are listed in Tables 3-5.

\section{Effects on Cord Blood Leptin}

There was no significant correlation between cord blood and maternal leptin levels $(r=$ $0.001, p=0.990)$ or prepregnancy BMI class $(r=0.064, p=0.607)$. Female offspring tended to have higher leptin levels than males $(10.2 \pm 8.2 \mathrm{vs} .6 .9 \pm 5.8 \mathrm{ng} / \mathrm{mL}, p=0.068)$. In multiple linear regression analysis, moderate-intensity activity in the third trimester $(\beta=0.265, p=$ $0.007)$ and offspring sex $(\beta=-0.220, p=0.025)$ explained $9.2 \%$ of the variance (Table 3 ).

\section{Influences on Maternal Leptin}

In regression analyses, maternal prepregnancy BMI (T0) $(\beta=0.602, p<0.001)$ and weight gain during pregnancy $(\beta=0.247, p=0.004)$ explained $35.5 \%$ of the variance in maternal leptin levels (Table 4).

\section{Effects on Offspring Weight Parameters}

Mean BMI increased by $3.6 \mathrm{~kg} / \mathrm{m}^{2}\left( \pm 1.6 \mathrm{~kg} / \mathrm{m}^{2}\right)$, and mean BMI-SDS decreased by 0.29 $( \pm 1.36)$ during the first year of life. Cord blood leptin inversely correlated with BMI-SDS change $(r=-0.269, p=0.027)$ in the first year. Infants whose change in BMI-SDS between U1 and U6 was higher than average had significantly lower leptin levels at birth when analyzed retrospectively ( $6.3 \pm 4.1$ vs. $10.7 \pm 8.7 \mathrm{ng} / \mathrm{mL}, p=0.008)$. In multiple linear regression analysis, cord blood leptin $(\beta=-0.222, p=0.074)$, maternal leptin $(\beta=0.414, p=0.001)$, and newborn sex $(\beta=0.385, p=0.003)$ explained $29.0 \%$ of the variance in the change in BMI-SDS from U1 to U6 (Table 5). 
Table 3. Multivariate analysis: cord blood leptin as an outcome variable (final model)
Table 4. Multivariate analysis: maternal leptin as an outcome variable (final model)
Telschow et al.: Association between Leptin and BMI-SDS in Early Life

\begin{tabular}{lrrr}
\hline & $\beta$ & $p$ & $\begin{array}{l}\text { Adjusted } \\
R^{2}\end{array}$ \\
& & & 0.091 \\
\hline Model 1 & & & \\
Weight gain during pregnancy, kg & 0.083 & 0.448 & \\
BMI before pregnancy, kg/m ${ }^{2}$ & -0.001 & 0.993 & \\
Total activity: 3rd trimester, METs & -0.270 & 0.217 & \\
Total upper arm area, cm ${ }^{2}$ & 0.294 & 0.160 & \\
Upper arm fat area, cm ${ }^{2}$ & -0.231 & 0.225 & \\
Moderate-intensity activity: & & & \\
$\quad$ 3rd trimester, METs & 0.519 & 0.017 & \\
Offspring sex & -0.234 & 0.022 & \\
\hline Model 6 & & 0.000 & 0.092 \\
Moderate-intensity activity: & & & \\
$\quad$ 3rd trimester, METs & 0.265 & 0.007 & \\
Offspring sex & -0.220 & 0.025 & \\
\hline
\end{tabular}

\begin{tabular}{lrrr}
\hline & $\beta$ & $p$ & $\begin{array}{l}\text { Adjusted } \\
R^{2}\end{array}$ \\
\hline Model 1 & & & 0.347 \\
Weight gain during pregnancy, kg & 0.206 & 0.025 & \\
BMI before pregnancy, kg/m ${ }^{2}$ & 0.450 & 0.001 & \\
Total activity: 3rd trimester, METs & -0.079 & 0.354 & \\
Total upper arm area, cm ${ }^{2}$ & 0.066 & 0.701 & \\
Upper arm fat area, cm ${ }^{2}$ & 0.100 & 0.522 & \\
Nutrition & -0.052 & 0.534 & \\
\hline Model 5 & & & 0.355 \\
Weight gain during pregnancy, kg & 0.247 & 0.004 & \\
BMI before pregnancy, kg/m ${ }^{2}$ & 0.602 & 0.000 & \\
\hline
\end{tabular}

Table 5. Multivariate analysis: change in BMI-SDS from U1 to U6 as an outcome variable (final model)

\begin{tabular}{lrrr}
\hline & $\beta$ & $p$ & $\begin{array}{l}\text { Adjusted } \\
R^{2}\end{array}$ \\
\hline Model 1 & & & 0.293 \\
Weight gain during pregnancy, kg & -0.085 & 0.568 & \\
BMI before pregnancy, kg/m ${ }^{2}$ & 0.147 & 0.345 & \\
Maternal leptin, ng/mL & 0.323 & 0.053 & \\
Cord blood leptin, ng/mL & -0.167 & 0.223 & \\
Birth weight percentile & -0.147 & 0.309 & \\
Offspring sex & 0.428 & 0.002 & \\
Total activity: 3rd trimester, METs & 0.007 & 0.956 & \\
\hline Model 5 & & & \multirow{2}{*}{0.290} \\
Maternal leptin, ng/mL & 0.414 & 0.001 & \\
Cord blood leptin, ng/mL & -0.222 & 0.074 & \\
Offspring sex & 0.385 & 0.003 & \\
\hline
\end{tabular}


Telschow et al.: Association between Leptin and BMI-SDS in Early Life

\section{Discussion}

To our knowledge, this is the first study to examine the association of maternal anthropometric and lifestyle factors to maternal and infant leptin levels at birth on infant BMI-SDS development up to 1 year of age taking sociodemographic factors into account.

Both maternal and infant leptin levels were distinctly linked to the development of BMI-SDS during the first year of life, although there was no association between both parameters. Brunner et al. [18] also observed no direct correlation between maternal and infant leptin concentrations supporting the two-compartment model of fetoplacental leptin regulation by Laml et al. [32], which states that cord blood leptin most likely has a fetal or placental origin, and, comparable to a noncommunicating model, there might be no placental transfer.

In terms of offspring weight development, high cord blood leptin was associated with a smaller change in BMI-SDS up to 1 year of age, thus, confirming the results of previous studies $[10,16,18]$. Kaar et al. [16] explained this by a negative feedback mechanism. High cord blood leptin levels may reduce appetite regulation in the hypothalamus and may, thus, lead to a lower weight gain. Boeke et al. [10] confirmed this inverse relationship during the first 3 years of life; with advancing age, however, a positive correlation between infant leptin levels and weight gain was observed.

In contrast, maternal leptin concentrations correlated positively with the change in infant BMI-SDS over the first year of life. In previous studies, the association between maternal leptin level and infant weight gain is inconsistent, possibly because they examined different time periods or did not relate maternal leptin data to those of the infants [10, 18, 33-35]. To our knowledge, this is the first study evaluating maternal leptin concentrations and infant weight gain during the first year of life. In contrast, the results published by Brunner et al. [18] refer to the first 2 years, and those of Boeke et al. [10] to 3 and 7 years of life. The authors suggest an inverse association between maternal leptin levels and infant weight as well as lean body mass development. Further studies are needed to investigate the influence of maternal leptin levels on neonatal BMI-SDS development during different time periods.

In the present study, maternal physical activity was positively associated with the infants' leptin levels but not with the change in BMI-SDS. In addition, gestational weight gain and maternal prepregnancy BMI affected maternal leptin levels but not BMI-SDS change.

In contrast to other studies [36,37], we did not find a direct association between maternal prepregnancy BMI or gestational weight and infants' physical development; however, cord blood and maternal leptin levels were associated with maternal BMI, gestational weight gain, and physical activity during pregnancy. In turn, leptin levels influenced the infant BMI-SDS; therefore, it can be tentatively postulated that a healthy lifestyle may generate lower maternal and higher infant leptin concentrations, thus, facilitating a lower BMI-SDS increase in the offspring. Moreover, because maternal BMI may be an indicator of lifestyle habits before pregnancy, maintaining a healthy lifestyle before pregnancy may play a vital role in this association. To establish effective preventive measures to reduce metabolic risk factors, it is crucial to identify further parameters that may influence infant weight development during the first year of life.

The strengths of this study include the careful control of confounders and the standardized measurement of offspring anthropometrics from U1 to U6 obtained by pediatricians. Because childhood BMI is particularly dependent on age and sex, we calculated the BMI-SDS for a more precise analysis. Another strength of this study is the high response rate to the questionnaires $(67.3 \%)$.

On the other hand, one limitation of this study is the assessment of physical activity by the questionnaire. Subjective measurements, which are simple and low in costs, are widely used in epidemiological studies [38]; however, it has been reported that physical activity, 
measured by recall questionnaires, can be over- or underestimated [39]. This could also apply to our study. Objective measurements like actigraphs would have been more precise; however, their use would not have been feasible in this study due to our retrospective study design and costs. Nevertheless, in future studies, a combination of both objective and subjective measurements of physical activity should be included.

Furthermore, participants were recruited only in the Obstetric Unit of the University of Bonn Medical School. Hence, our sample might not be representative of the general population.

Following Boeke et al. [10], we defined cord blood leptin as the newborns' leptin concentration because placental leptin is largely released into the maternal circulation [9]. We only analyzed total leptin concentrations and did not differentiate between free and bound leptin. This could limit our results because the free form might be the more important biological determinant [40]. So far, only Brunner et al. [18] have investigated both forms of leptin in the context of pregnancy and children's weight gain and found no significant differences.

In conclusion, high maternal and low cord blood leptin levels are associated with a higher BMI-SDS gain in the first year of life. Maternal leptin levels are influenced by prepregnancy BMI and weight gain during pregnancy. Cord blood leptin concentrations are influenced by sex as well as maternal moderate-intensity physical activity during the third trimester. Therefore, an active maternal lifestyle, maternal BMI, and the weight gain during pregnancy may indirectly influence an infant's change in BMI-SDS during the first year, partly explained by its influence on leptin levels. In terms of obesity prevention, it is important to focus on infant weight development in the first year, taking potential influencing factors, such as maternal lifestyle and anthropometry, into account.

\section{Acknowledgments}

We thank the hospital staff, including doctors, nurses and midwives, for their valuable help throughout the study. Furthermore, we thank all women who participated in the study. We would also like to thank Erica and Daniel Landerson and Katharina Gross for critically reviewing the manuscript. We are also grateful to Iris Paffenholz for helping us process blood samples.

\section{Statement of Ethics}

The ethics committee in Bonn approved the study design and consent form (269/13). The authors declare that all experiments on human subjects were conducted in accordance with the Declaration of Helsinki, and that all procedures were carried out with the adequate understanding and written consent of the subjects. The authors also certify that formal approval to conduct the experiments described has been obtained from the human subjects' review board of their institution and could be provided upon request.

\section{Disclosure Statement}

There are no conflicts of interest. This research did not receive any specific grant from funding agencies in the public, commercial, or not-for-profit sectors. 
Telschow et al.: Association between Leptin and BMI-SDS in Early Life

\section{Author Contributions}

A.T., N.F., and C.G., designed the study; N.F., A.T., C.D., C.E., A.F., and W.M.M. conducted the study and collected the data; A.T., N.F., and C.G. analyzed the data; U.G. and J.D. contributed to the discussion and reviewed the manuscript; A.T., N.F., and C.G. wrote the manuscript. All authors gave final approval to the submitted and published version.

\section{References}

1 Llewellyn A, Simmonds M, Owen CG, Woolacott N. Childhood obesity as a predictor of morbidity in adulthood: a systematic review and meta-analysis. Obes Rev. 2016 Jan;17(1):56-67.

2 Schienkiewitz A, Brettschneider A-K, Damerow S, Schaffrath Rosario A. Übergewicht und Adipositas im Kindes- und Jugendalter in Deutschland - Querschnittergebnisse aus KiGGS Welle 2 und Trends. J Health Monitoring. 2018;3(1)16-23.

3 Shrewsbury V, Wardle J. Socioeconomic status and adiposity in childhood: a systematic review of crosssectional studies 1990-2005. Obesity (Silver Spring). 2008 Feb;16(2):275-84.

4 Mensink GB, Schienkiewitz A, Haftenberger M, Lampert T, Ziese T, Scheidt-Nave C. [Overweight and obesity in Germany: results of the German Health Interview and Examination Survey for Adults (DEGS1)]. Bundesgesundheitsblatt Gesundheitsforschung Gesundheitsschutz. 2013 May;56(5-6):786-94. German.

5 Baeten JM, Bukusi EA, Lambe M. Pregnancy complications and outcomes among overweight and obese nulliparous women. Am J Public Health. 2001 Mar;91(3):436-40.

6 Muktabhant B, Lawrie TA, Lumbiganon P, Laopaiboon M. Diet or exercise, or both, for preventing excessive weight gain in pregnancy. Cochrane Database Syst Rev. 2015 Jun;15(6):CD007145.

7 Schellong K, Schulz S, Harder T, Plagemann A. Birth weight and long-term overweight risk: systematic review and a meta-analysis including 643,902 persons from 66 studies and 26 countries globally. PLoS One. 2012; 7(10):e47776.

8 Brennan AM, Mantzoros CS. Drug Insight: the role of leptin in human physiology and pathophysiologyemerging clinical applications. Nat Clin Pract Endocrinol Metab. 2006 Jun;2(6):318-27.

9 Linnemann K, Malek A, Sager R, Blum WF, Schneider H, Fusch C. Leptin production and release in the dually in vitro perfused human placenta. J Clin Endocrinol Metab. 2000 Nov;85(11):4298-301.

10 Boeke CE, Mantzoros CS, Hughes MD, L Rifas-Shiman S, Villamor E, Zera CA, et al. Differential associations of leptin with adiposity across early childhood. Obesity (Silver Spring). 2013 Jul;21(7):1430-7.

11 Kwon S, Janz KF, Letuchy EM, Burns TL, Levy SM. Association between body mass index percentile trajectories in infancy and adiposity in childhood and early adulthood. Obesity (Silver Spring). 2017 Jan;25(1):166-71.

12 Leunissen RW, Kerkhof GF, Stijnen T, Hokken-Koelega A. Timing and tempo of first-year rapid growth in relation to cardiovascular and metabolic risk profile in early adulthood. JAMA. 2009 Jun;301(21):2234-42.

13 Ekelund U, Ong KK, Linné Y, Neovius M, Brage S, Dunger DB, et al. Association of weight gain in infancy and early childhood with metabolic risk in young adults. J Clin Endocrinol Metab. 2007 Jan; 92(1):98-103.

14 Clapp JF 3rd, Kiess W. Effects of pregnancy and exercise on concentrations of the metabolic markers tumor necrosis factor $\alpha$ and leptin. Am J Obstet Gynecol. 2000 Feb;182(2):300-6.

15 Alessa HB, Chomistek AK, Hankinson SE, Barnett JB, Rood J, Matthews CE, et al. Objective Measures of Physical Activity and Cardiometabolic and Endocrine Biomarkers. Med Sci Sports Exerc. 2017 Sep;49(9):1817-25.

16 Kaar JL, Brinton JT, Crume T, Hamman RF, Glueck DH, Dabelea D. Leptin levels at birth and infant growth: the EPOCH study. J Dev Orig Health Dis. 2014 Jun;5(3):214-8.

17 Mantzoros CS, Rifas-Shiman SL, Williams CJ, Fargnoli JL, Kelesidis T, Gillman MW. Cord blood leptin and adiponectin as predictors of adiposity in children at 3 years of age: a prospective cohort study. Pediatrics. 2009 Feb; 123(2):682-9.

18 Brunner S, Schmid D, Hüttinger K, Much D, Brüderl M, Sedlmeier EM, et al. Effect of reducing the n-6/n-3 fatty acid ratio on the maternal and fetal leptin axis in relation to infant body composition. Obesity (Silver Spring). 2014 Jan;22(1):217-24.

19 Flöck A, Weber SK, Ferrari N, Fietz C, Graf C, Fimmers R, et al. Determinants of brain-derived neurotrophic factor (BDNF) in umbilical cord and maternal serum. Psychoneuroendocrinology. 2016 Jan;63:191-7.

20 Deibert C, Ferrari N, Flöck A, Merz WM, Gembruch U, Lehmacher W, et al. Adipokine-myokine-hepatokine compartment-system in mothers and children: An explorative study. Contemp Clin Trials Commun. 2016 Feb; $3: 1-5$.

21 World Health Organization. Obesity - Preventing and Managing the Global Epidemic: Report on a WHO Consultation. Geneva: World Health Organization; 2000.

22 Jackson AS, Pollock ML, Ward A. Generalized equations for predicting body density of women. Med Sci Sports Exerc. 1980;12(3):175-81.

23 Rolland-Cachera MF, Brambilla P, Manzoni P, Akrout M, Sironi S, Del Maschio A, et al. Body composition assessed on the basis of arm circumference and triceps skinfold thickness: a new index validated in children by magnetic resonance imaging. Am J Clin Nutr. 1997 Jun;65(6):1709-13. 
Telschow et al.: Association between Leptin and BMI-SDS in Early Life

24 Graf C, Koch B, Kretschmann-Kandel E, Falkowski G, Christ H, Coburger S, et al. Correlation between BMI, leisure habits and motor abilities in childhood (CHILT-project). Int J Obes Relat Metab Disord. 2004 Jan;28(1): 22-6.

25 Chasan-Taber L, Schmidt MD, Roberts DE, Hosmer D, Markenson G, Freedson PS. Development and validation of a Pregnancy Physical Activity Questionnaire. Med Sci Sports Exerc. 2004 Oct;36(10):1750-60.

26 Ainsworth BE, Haskell WL, Whitt MC, Irwin ML, Swartz AM, Strath SJ, et al. Compendium of physical activities: an update of activity codes and MET intensities. Med Sci Sports Exerc. 2000 Sep;32(9 Suppl):S498-504.

27 Meltzer HM, Brantsaeter AL, Ydersbond TA, Alexander J, Haugen M. Methodological challenges when monitoring the diet of pregnant women in a large study: experiences from the Norwegian Mother and Child Cohort Study (MoBa). Matern Child Nutr. 2008 Jan;4(1):14-27.

28 Hoffmann I, Spiller A. Auswertung der Daten der Nationalen Verzehrsstudie II (NVS II): eine integrierte verhaltens- und lebensstilbasierte Analyse des Bio-Konsums. http://www.orgprints.org/18055/.

29 Thaiss H, Klein R, Schumann EC, Ellsäßer G, Breitkopf H, Reinecke H, et al. Früherkennungsuntersuchungen als Instrument im Kinderschutz. Bundesgesundheitsblatt Gesundheitsforschung Gesundheitsschutz. 2010 Oct;53(10):1029-47.

30 Kromeyer-Hauschild K, Wabitsch M, Kunze D, Geller F, Geiß HC, Hesse V, et al. Perzentile für den Body-massIndex für das Kindes- und Jugendalter unter Heranziehung verschiedener deutscher Stichproben. Monatsschr Kinderheilkd. 2001 AUG;149(8):807-18.

31 Arbeitsgemeinschaft Adipositas im Kindes- und Jugendalter. S3-Leitlinie Therapie der Adipositas im Kindesund Jugendalter. [2017, Oct 28]. Available from: http://www.aga.adipositas-gesellschaft.de/fileadmin/PDF/ Leitlinien/Leitlinie-AGA-S3-2009.pdf.

32 Laml T, Hartmann BW, Ruecklinger E, Preyer O, Soeregi G, Wagenbichler P. Maternal serum leptin concentrations do not correlate with cord blood leptin concentrations in normal pregnancy. J Soc Gynecol Investig. 2001 Jan-Feb;8(1):43-7.

33 Hinkle SN, Rawal S, Liu D, Chen J, Tsai MY, Zhang C. Maternal adipokines longitudinally measured across pregnancy and their associations with neonatal size, length, and adiposity. Int J Obes (Lond). 2019 Jul;43(7):142234.

34 Geary M, Pringle PJ, Persaud M, Wilshin J, Hindmarsh PC, Rodeck CH, et al. Leptin concentrations in maternal serum and cord blood: relationship to maternal anthropometry and fetal growth. Br J Obstet Gynaecol. 1999 Oct; 106(10):1054-60.

35 Uebel K, Pusch K, Gedrich K, Schneider KT, Hauner H, Bader BL. Effect of maternal obesity with and without gestational diabetes on offspring subcutaneous and preperitoneal adipose tissue development from birth up to year-1. BMC Pregnancy Childbirth. 2014 Apr;14(1):138.

36 Zhang W, Niu F, Ren X. Association of maternal pre-pregnancy body mass index and gestational weight gain with Chinese infant growth. J Paediatr Child Health. 2019 Jun;55(6):673-9.

37 Hinkle SN, Sharma AJ, Swan DW, Schieve LA, Ramakrishnan U, Stein AD. Excess gestational weight gain is associated with child adiposity among mothers with normal and overweight prepregnancy weight status. J Nutr. 2012 Oct;142(10):1851-8.

38 Harrison CL, Thompson RG, Teede HJ, Lombard CB. Measuring physical activity during pregnancy. Int J Behav Nutr Phys Act. 2011 Mar;8(1):19.

39 Bell R, Tennant PW, McParlin C, Pearce MS, Adamson AJ, Rankin J, et al. Measuring physical activity in pregnancy: a comparison of accelerometry and self-completion questionnaires in overweight and obese women. Eur J Obstet Gynecol Reprod Biol. 2013 Sep;170(1):90-5.

40 Sinha MK, Opentanova I, Ohannesian JP, Kolaczynski JW, Heiman ML, Hale J, et al. Evidence of free and bound leptin in human circulation. Studies in lean and obese subjects and during short-term fasting. J Clin Invest. 1996 Sep;98(6):1277-82. 